\title{
KOREKSI HUKUM ISLAM TERHADAP HUKUM JAHILIAH
}

\author{
Mukran H. Usman \\ Sekolah Tinggi Ilmu Islam dan Bahasa Arab (STIBA) Makassar \\ Email :mukran@stiba.ac.id \\ Akhmad Hanafi Dain Yunta \\ Sekolah Tinggi Ilmu Islam dan Bahasa Arab (STIBA) Makassar \\ Email : ahmadhanafi@gmail.com
}

\begin{abstract}
Keywords : law, jahiliyyah, polygamy, dowry, iddah
\end{abstract} \begin{abstract}
Islamic law came to bring justice and benefit. The law of jahiliah in some cases were corrected but not removed, so this also strengthened the understanding that the sharia Law of the previous people were originated from Allah who were improved, corrected, and adjusted. This study aimed to provide an explanation and knowledge concerning the law of jahiliah that were corrected by Islamic law without being removed. The research method used was the literature study with normative approach and was supported by a historical approach. The result shows that it is clear that Islamic justice did not necessarily eradicate some of the laws of jahiliah, such as: Polygamy, dowry, and the period of idah. On the contrary, Islam eliminates the technical that are unjust and still consider that law as part of Islamic law.
\end{abstract}

Kata kunci :
hukum, jahiliah, poligami,
mahar, iddah

\begin{tabular}{l} 
ABSTRAK \\
\hline Hukum Islam datang untuk membawa keadilan dan kemaslahatan. \\
Hukum jahiliah pada beberapa hal mendapatkan koreksi tapi bukan \\
menghapus, sehingga hal ini juga menguatkan pemahaman kepada \\
hukum-hukum syariat umat terdahulu bahwa hukum-hukum itu \\
berasal dari Allah Ta'ala yang mendapatkan penyempurnaan dan \\
perbaikan serta penyesuaian. Penelitian ini bertujuan untuk \\
memberikan penjelasan dan pengetahuan tentang hukum-hukum \\
jahiliah yang mendapatkan koreksian dari hukum Islam tanpa \\
menghapus hukum tersebut. Metode penelitian yang digunakan \\
adalah dengan kajian literatur kepustakaan dengan pendekatan \\
normatif dan didukung dengan pendekatan histroris. Hasil \\
penelitian menunjukkan bahwa nampak jelas keadilan Islam yang \\
tidak serta merta menghapus beberapa hukum jahiliah, seperti: \\
poligami, mahar dan masa Idah. Sebaliknya, Islam menghapus \\
bagian sisi teknis yang nampak ketidakadilannya dengan tetap \\
menjadikan hukum itu sebagai bagian dari hukum Islam.
\end{tabular}




\section{PENDAHULUAN}

Masa jahiliyyah dengan berbagai hukum yang berlaku di masyarakat memberikan gambaran akan tatanan kehidupan bermasyarakat yang dipenuhi dengan berbagai ketidakadilan. Abu al-Hasan al-Nadawi menggambarkan kondisi masyarakat jahiliah dengan mengatakan: "Pada masa itu, pada umumnya tidak terdapat suatu bangsa yang mempunyai tabi' at baik. Tidak ada masyarakat yang berdiri di atas landasan akhlak dan keutamaan, tidak ada pemerintahan yang ditegakkan atas dasar keadilan dan kasih sayang. Tidak ada pimpinan dan pemerintahan yang bertindak atas dasar ilmu dan pengetahuan, dan tidak ada agama yang benar sebagaimana yang diwariskan oleh para nabi. ${ }^{1}$

Al-Qur'an telah menyebutkan tentang kondisi masyarakat jahiliah sebelum Islam dengan kondisi yang sangat tidak berperikemanusiaan. Yang menjadi banyak korban dari kejahiliaan tersebut adalah wanita, dari sejak wanita itu lahir, sampai ia menikahpun mengalami kondisi yang tidak adil. Wanita sejak ia lahir sudah tidak disukai, Allah Subhānahu wa Ta'āla. berfirman dalam Q.S. AlNahl/16: 58 yang artinya: "Dan apabila salah seorang dari mereka diberi kabar dengan kelahiran anak perempuan, hitamlah mukanya dan dia sangat marah. Ia menyembunyikan dirinya dari orang banyak, disebabkan buruknya berita yang disampaikan kepadanya. Apakah dia akan memeliharanya dengan menanggung kehinaan ataukah akan menguburkannya kedalam tanah (hidup-hidup)? Ketahuilah, alangkah buruknya apa yang mereka tetapkan." Dan bagaimana kondisi wanita di masa mereka dewasa, disaat mereka menjadi istri, disaat mereka akan menikah, maka sangat jelas ketidakadilan yang mereka dapatkan sebagaimana yang dijelaskan dalam bab pembahasan artikel ini.

Dalam kondisi bangsa Arab yang demikian buruk, Allah Subhānahu wa Ta'āla. kemudian mengutus Nabi Muhammad șallallāhu 'alayhi wa sallam untuk membawa bangsa Arab ke dalam Islam, memimpin kehidupan mereka, menghilangkan segala bentuk kerusakan moral dan akhlak. Sayyid Qutub dalam kitabnya mā'alim fí al-Toríq mengatakan: "Masyarakat (arab) dibersihkan dari segala kerusakan dan kezaliman yang ada di masyarakat, maka tegaklah hukum (syariat) Islam, menegakkan keadilan dengan keadilan Islam, dan menimbang dengan timbangan Islam, mengangkat panji keadilan dengan nama Allah semata

\footnotetext{
${ }^{1}$ Abu al-Hasan al-Nadawī, Mādza Khasira al-Alam bỉ Inhitoti $\bar{i}$ al-Musliminn (Cet. 1; Mesir: Maktabatu al-Imān Mansūrah, t.th), h. 63.
} 
dengan memberi nama 'Bendera Islam' (bendera itu) telah menghapus segala kerusakan, dituliskan di dalam bendera itu Là Ilāha Illallāh."’

Kehadiran Rasulullah șallallāhu 'alayhi wa sallam yang membawa ajaran Islam adalah sebuah karunia dan nikmat yang besar. Dalam buku Al-Qiyām wa al-Ibar wa al-Amtsāl fì al-Qur'ān oleh Fāyiq Muhammad al-Ganāyim dikatakan: "Sesungguhnya risalah Islam membawa umat (bangsa arab) dari segala sisi kehidupan kepada perubahan, dari kekufuran kepada Islam, dari kesesatan kepada hidayah, merubah kehidupan politik mereka, kehidupan sosial masyarakat, dan pola berfikir mereka."3

Hal yang mendapat perhatian besar dari ajaran Islam yang dibawa oleh Rasulullah șallallāhu 'alayhi wa sallam dalam perbaikannya, yang kemudian penulis mengangkat dalam artikel ini adalah masalah poligami, idah dan mahar. Ketiga masalah ini telah mendapatkan perhatian yang besar dalam ajaran Islam, kaitannya dengan penegakan keadilan, yang di masa jahiliah, masalah ini tampak memberikan ketidakadilan dan perlakuan diskriminatif terhadap wanita.

Penelitian ini menggunakan pendekatan yuridis dan normatif dan didukung dengan pendekatan historis, alih-alih berupa kajian literatur kepustakaan (library research). Untuk pengumpulan data, peneliti terlebih dahulu mengumpulkan sumber data primer dan sekunder dengan menjadikan sumber data primer sebagai bahan utama dan kemudian dijelaskan oleh sumber data sekunder, seperti beberapa kutipan ayat-ayat al-Qur'an lalu dikuatkan dengan penafsiran para ulama. Demikian pula hadis Nabi șallallāhu 'alayhi wa sallam dengan menjabarkan beberapa penjelasan hadis tersebut dari para ulama. Untuk beberapa pengertian, penulis menggunakan buku-buku rujukan berbahasa Arab sebagai sumber data, demikian pula sebagian besar isi dari pada penelitian ini dengan banyak menjadikan sumber data dari buku-buku induk berbahasa Arab.

Untuk menjaga amanah ilmiah pada penelitian ini, peneliti mengambil dan mencantumkan beberapa hasil penelitian yang terdahulu atau relevan, alih-alih membahas tentang bagian-bagian yang ada pada penelitian ini. Beberapa penelitian tersebut di antaranya penelitian yang dilakukan oleh Hermanto tentang Islam, poligami dan perlindungan kaum perempuan, ${ }^{4}$ dalam mana

${ }^{2}$ Sayyid Qutub, Ma'älim fỉ al-Torīq (Cet. 6; Beirut: Dār al-Syurūq, 1399 H/1979 M), h. 29.

${ }^{3}$ Fāyiq Muhammad Ganāyim, al-Qiyam wa al-Ibar, wa al-Amtsāl fí al-Qur'an al-Karīm (Urdun: Dārul Ma'mun 「ì al-Munsyir wa al-Tauzi'), h. 13.

${ }^{4}$ Agus Hermanto, Islam, poligami dan perlindungan perempuan, Kalām 9, no. 1 (2015): h. 167. 
pembahasannya adalah seputar bagaimana Islam mengatur hukum poligami untuk perlindungan kaum perempuan, tanpa membahas bagaimana hakikat poligami di masa jahiliah dan di masa Islam. Ihwal mahar, sebuah penelitian berjudul "Tinjauan fiqih tentang mahar sebagai pemberian atau pembelian" dilakukan oleh Khafidhoh ${ }^{5}$ yang membahas tentang mahar yang merupakan pemberian, dan bukan pembelian. Demikian pula untuk idah, sebuah penelitian berjudul "Idah dan ihdad dalam Islam: pertimbangan legal formal dan etik moral" yang dilaksanakan oleh Moqsith, ${ }^{6}$ dalam mana lebih kepada kajian fungsi dari pada pensyariatan idah, dan belum secara utuh membahas apa yang menjadi fokus pada penelitian ini.

Hal yang baru dari apa yang penulis simpulkan dengan beberapa penelitian sebelumnya, bahwa penulis selain menjelaskan perbandingan antara poligami, mahar, dan idah di masa jahiliah dengan masa Islam. Penulis juga menyebutkan beberapa bukti akan kelebihan yang ada pada poligami, mahar dan idah dalam Islam dengan menyebutkan landasan syariat berupa dalil-dalil yang sahih.

Berdasarkan dari landasan perkara inilah, peneliti kemudian ingin mengkaji bagaimana kelebihan-kelebihan yang telah diberikan oleh Islam sebagai wujud untuk memberikan keadilan kepada wanita atas hak-hak mereka yang sekian lama kaum wanita tidak mendapatkannya. Adapun wanita adalah sebagai bagian yang tidak terpisahkan dalam membawa umat manusia kepada penegakan keadilan yang sesungguhnya. Nabi șallallāhu 'alayhi wa sallam bersabda yang artinya: "Sesungguhnya wanita (dalam masalah hukum syar'i) adalah saudara kandung laki-laki."”

\section{PEMBAHASAN}

\section{Poligami}

\section{Pengertian Poligami}

Kata poligami, secara etimologi berasal dari bahasa Yunani, yaitu polus yang

\footnotetext{
${ }^{5}$ Riadhiyati Khafidhoh, "tinjauan fiqih tentang mahar sebagai pemberian atau pembelian", Skripsi (Jepara: Fak. Syariah dan Hukum UNISNU Jepara, 2015), h. 1-4

${ }^{6} \mathrm{Abd}$ Moqsith Ghazali, iddah dan ihdād dalam islam: pertimbangan legal formal dan etik moral (Jakarta: LkiS Rahima, 2002 M), h. 138.

${ }^{7}$ Abu Daud al-Sajastāni, Sunan Abi Daud, Juz 1 (Beirut: al-Maktabah al-Asriyah, t.th), h. 61.
} 
berarti banyak dan gamos yang berarti perkawinan. ${ }^{8}$ Sementara dalam pengertian terminologi disebutkan bahwa poligami adalah sistem perkawinan yang salah satu pihak memiliki atau mengawini beberapa lawan jenisnya dalam waktu yang bersamaan. ${ }^{9}$

\section{Poligami Sebelum Islam}

Poligami adalah perkara yang sudah ada sebelum Islam. Bahkan, poligami adalah budaya yang hampir ada pada semua bangsa dengan ragam dan corak yang berbeda. Bangsa Yunani, bangsa Romawi, bangsa Babilonia, bangsa Mesir, Yahudi, dan bangsa Eropa terkhusus pada abad pertengahan adalah merupakan bangsa yang mempraktekkan poligami yang tidak terbilang jumlahnya (jumlah istri), tidak mengenal syarat harus adil (sebagaimana dalam Islam), dan tujuan mereka berpoligami sebatas pada syahwat semata. ${ }^{10}$ Apa yang ada pada bangsabangsa tersebut tentang praktik poligami tanpa batas, tidak jauh berbeda dengan apa yang terjadi pada bangsa arab, terkhusus pada masa jahiliah sebelum datangnya Islam. Imam al-Tobari dalam kitabnya Jä'mi al-Bayān mengatakan: "Adalah laki-laki Qurays di masa jahiliah menikahi wanita sampai sepuluh bahkan lebih atau kurang."11 Hal itu tergambarkan dalam beberapa pengakuan dari para sahabat rhadiallahu 'anhu yang masuk Islam dan menyampaikannya kepada Rasulullah șallallāhu 'alayhi wa sallam tentang jumlah istri mereka.

Dari hadis yang diriwayatkan oleh Imam Abu Daud bahwa al-Hāris ibn Qais al-Asadi berkata kepada Rasulullah șallallāhu 'alayhi wa sallam: "Saya masuk Islam dan saya memiliki 8 istri, lalu saya sampaikan kepada Nabi șallallāhu 'alayhi wa sallam dan memerintahkan saya untuk memilih 4 dari mereka."12 Al-Imām As-Syāfi' 'i rahimahullah dalam musnadnya juga berkata bahwa Naufal bin Muayyiah al-Dailami berkata: "Saya masuk Islam dan memiliki 5 (lima) istri, maka Nabi șallallāhu 'alayhi wa sallam berkata kepada saya, pilih 4 (empat) dari mereka yang engkau mau dan ceraikan yang lain."13

\section{Poligami Dalam Islam}

${ }^{8}$ Haris Hidayatullah, “Adil Dalam Poligami Perspektif Ibnu Hazm”, Studi Islam 6, no 2 (2015): h. 207-236.

${ }^{9}$ Muhammad Arif Mustofa, "Poligami Dalam Hukum Agama Dan Negara", al-Imarah 2, no. 1 (2018): h. 48.

${ }^{10}$ Ali Abdul Wāhid Wāfí, "Hukuk al-Insān fĩ al-Islam", (1429 H), h. 123.

${ }^{11}$ Muhammad ibn Jarir al-Tobari, Jāmi' al-Bayān, Juz 7 (Cet. 1; Beirut: Muassatu al-Risālah, $2000 \mathrm{M} / 1420 \mathrm{H})$, h. 552.

${ }^{12}$ Abu Daud Sulaiman al-Sajastāni, Sunan Abu Daud Ti al-Arnōt, Juz 3(Cet. I; Beirut: Dār alRisālah al-Âlamiyah, 2009 M/1430 H), h. 556.

${ }^{13}$ Mujiddin al-Jazāri ibn al-Asīr, Al-Syāfi 'i fì Syarhi Musnadi al-Syāfíí, Juz 4 (Cet. 1; Riyad: Maktabah al-Rusydi, 2005 M/1426 H), h. 388. 
Ketika Islam datang, beberapa syariat yang ada di masyarakat jahiliah Arab tetap dilakukan oleh sebagian besar sahabat radiallāhu 'anhu sebagaimana yang telah dijelaskan sebelumnya. Sampai kemudian datang koreksinya dari syariat Islam. Poligami adalah termasuk syariat yang ada sebelum Islam yang tidak dihapus hukumnya, namun telah mendapatkan koreksian dari syariat Islam. Dalam syariat Islam yang tertuang langsung dalam ayat-ayat al-Qur'an memberikan keterangan tentang syariat poligami. Di antaranya adalah firman Allah Subhānahu wa Ta'āla dalam Q.S. An-Nisa'/4: 3 berfirman:

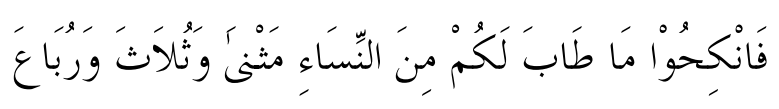

Terjemahnya: "Maka nikahilah wanita-wanita lain yang kamu senangi: dua, tiga, atau empat."

Ayat ini dijadikan sumber pegangan oleh para ulama yang memandang akan pensyariatan poligami. Baik ulama salaf (terdahulu) maupun ulama khalaf (kontemporer). Al-Imam As-Syāfi'i rahimahullah memberikan penjelasan tentang ayat tersebut bahwa sunah Rasulullah șallallāhu 'alayhi wa sallam telah menjelaskan ayat tersebut bahwa Allah membatasi seorang laki-laki untuk untuk menikahi empat orang wanita saja dan mengharamkan lebih dari empat. ${ }^{14}$ Demikian pula al-Imam Ibnu Katsir dalam tafsirnya terhadap Q.S. An-Nisa'/4: 3 mengatakan bahwa "Nikahilah wanita sebagaimana yang engkau mau, bila engkau mau maka nikahilah 2 wanita, dan bila engkau mau maka nikahilah 3 wanita, dan bila engkau mau maka nikahilah 4 wanita". ${ }^{15}$

Alasan bahwa Islam membatasi empat orang istri saja tentu untuk kemaslahatan dan kebaikan. Menurut Wahbah Al-Zuhaili dalam bukunya alFiqhu al-Islami wa Adillatuhu, beliau mengatakan tentang alasan pembatasan poligami: "Bahwa seorang laki-laki yang memiliki lebih dari empat istri sangat diyakini akan terjadi penzoliman kepada mereka dengan ketidakmampuan suami dalam menunaikan kewajibannya. Hal itu dikarenakan yang nampak pada kebanyakan laki-laki adalah ketidakmampuan dalam menunaikan hak-hak istri" ${ }^{16}$ Bahkan beliau, pada halaman 6668 dalam bukunya lebih menjelaskan secara teknis tentang mengapa syariat membatasi pada empat istri saja. Beliau mengatakan: "Sebab mengapa syariat membatasi empat istri, bahwa hal ini

\footnotetext{
${ }^{14}$ Muhammad ibn Idris al-Syāfi'ì, Tafsir al-Imām al-Syāfíĭ, Juz 2 (Cet. I; Saudi Arabia: Dār al-Tadmūriyah, $2006 \mathrm{M} / 1427 \mathrm{H})$, h. 515.

${ }^{15}$ Ibnu Katsīr, Tafsir al-Qur'ân al-Adzim, Juz 2 (Cet. 2; Riyad: Dārun Thoyyibah Iì al-Nasyrī wa al-Tauzi', 1999 M/1420 H), h. 209.

${ }^{16}$ Wahbah al-Zuhaili, Al-Fiqhu al-Islāmi wa Adillatuhu, Juz 9 (Cet. 4; Damaskus: Dār alFikr, 2011 M), h. 6669.
} 
sejalan dengan pandangan manusia dengan landasan akan kemampuan, dan keinginan yang harus mereka penuhi dalam sebulan. Dengan perhitungan bahwa dalam sebulan setiap istri memiliki waktu sepekan bersama suami (berbeda hal apabila memiliki lima istri)". ${ }^{17}$ Saguni, M. K., juga menambahkan bahwa makna keadilan yang dituntut pada Q.S. An-Nisa'/4: 129 bagi seorang laki-laki yang bepoligami adalah keadilan lahiriyah, seperti pembagian malam, pemberian nafkah dan pergaulan yang baik. ${ }^{18}$ Rahman, R. A., juga mengimbuhkan bahwa yang dimaksud dengan keadilan dalam berpoligami adalah pembagian hak kepada masing-masing istri. ${ }^{19}$ Dengan demikian, hakikat adil dalam ayat tersebut berkonsekuensi pada proporsionalitas suami terhadap pemberian waktu, materi, dan kasih sayang terhadap istinya.

Oleh karena begitu lebarnya praktek poligami di masa jahiliah sehingga batasan-batasan kehormatan tidak lagi memiliki arti. Maraknya praktek poligami tanpa batas, sampai wanita yang pernah menjadi istri bapak anakpun bisa dinikahi oleh anaknya (anak tiri) tersebut. Diriwayatkan oleh Ibnu Abi Hātim dari bapaknya, bahwa Abu Qois seorang anshar yang dikenal kesolehannya meninggal dunia, maka istrinya (ibu tiri) dilamar oleh anaknya. Maka wanita tersebut berkata: 'Saya telah menganggap engkau sebagai anakku dan engkau termasuk orang yang saleh dari kaummu'. Kemudian (kembali) wanita itu berkata: 'Saya akan datang kepada Rasulullah șallallāhu 'alayhi wa sallam dan bertanya'. Sesampainya di rumah Rasulullah maka wanita itu bertanya, wahai Rasulullah șallallāhu 'alayhi wa sallam, sesungguhnya Abu Qois telah meninggal dunia, dan salah seorang anaknya melamarku yang anak tersebut telah saya anggap sebagai anak sendiri dan termasuk anak yang saleh dari kaumnya, maka apa pendapatmu wahai Rasulullah șallallāhu 'alayhi wa sallam. Lalu Nabi șallallāhu 'alayhi wa sallam memerintahkannya untuk kembali, dan turunlah firman Allah Subhānahu wa Ta'āla dalam Q.S. An-Nisa'/4: 22 yang artinya: "Dan janganlah nikahi wanita-Wanita yang merupakan bekas istri bapakbapakmu. ${ }^{\text {20 }}$

\section{Mahar}

\section{Pengertian Mahar}

${ }^{17}$ Wahbah al-ZuhaiTi, Al-Fiqhu al-Isläm wa Adillatuhu, h. 6760.

${ }^{18}$ Saguni, M. K. (2018). Meluruskan Beberapa Persepsi tentang Poligami (Tafsir Surat alNisa'Ayat 3 dan 129). NUKHBATUL'ULUM: Jurnal Bidang Kajian Islam, 4(2), 161-172.

${ }^{19}$ Rahman, R. A. (2016). Konsep Keadilan dalam al-Quran. NUKHBATUL'ULUM: Jurnal Bidang Kajian Islam, 2(1), 167-175.

${ }^{20}$ Ibnu Abi Hatim, Tafsir al-Qur'ān al-Azìm lì ibn Abi Hätim, Juz 3 (Cet. 3; Saudi Arabia: Maktabah Naz̄ar Mustafa al-Baz̄, 1995 M/1419 H), h. 909 
Mahar dalam bahasa arab disebut dengan "al-shodā" yang jamak katanya adalah "muhūrun." ${ }^{21}$ Adapun "al-shodāq" adalah: harta yang wajib diberikan oleh seorang lelaki kepada wanita yang akan dinikahinya. ${ }^{22}$ Dan sebab penamaan mahar dengan "al-shodāq" adalah agar betul-betul diketahui dengan "al-sidqu" (jujur) akan keinginan calon suami terhadap calon istri. ${ }^{23}$ Adapun secara terminologi, arti mahar adalah harta yang wajib diberikan pada saat akad nikah bagi seorang laki-laki (calon suami) sebagai pengganti dari manfaat yang akan didapatkannya dari wanita calon istri. ${ }^{24}$

\section{Mahar Sebelum Islam}

Mahar wanita yang dinikahi sebelum Islam adalah menjadi milik dari wali nikah wanita tersebut. Hal itu disebutkan dalam beberapa buku tafsir para ulama, seperti Al-Imām al-Zamahsyarīi, ${ }^{25}$ Al-Imām Al-Radzìi, ${ }^{26}$ Al-Imām Al-Thontowī, ${ }^{27}$ dan ulama lainnya yang menyebutkan bahwa para wali wanita tersebut yang mengambil mahar nikah dari calon suami yang akan menikahinya. Bahkan ada satu bentuk pernikahan di masa jahiliah yang sama sekali tidak memberikan mahar kepada perempuan yang disebut dengan nikah syighär. Dalam kitab alMausūatu al-Fiqhiyah disebukan bahwa arti nikah syighār adalah nikah yang begitu dikenal di masyarakat jahiliah, dalam mana seorang laki-laki berkata kepada laki-laki lainnya, "Nikahkan saya dengan saudarimu, atau anak perempuanmu, atau wanita yang engkau tanggung, dan saya juga akan menikahkanmu dengan saudari perempuanku, atau anak perempuanku, atau wanita yang di bawah tanggunganku dan tanpa ada mahar yang diberikan, dan dengan cara seperti itu maka, maka itulah pengganti daripada mahar." ${ }^{28}$ Adapun Nabi șallallāhu 'alayhi wa sallam telah melarang pernikahan syighār yang tanpa

${ }^{21}$ Jamāluddin ibn Mandzūr, Lisānul Arab Juz 5 (Cet. 3; Beirut: Dārun Shōdirūn, 1414 H), h. 184.

${ }^{22}$ Taqiyuddin al-Syāfi'’i, Kifāyatu al-Akhyār fĭ Halli Goyatu al-Ikhtisōr (Cet. 1; Damaskus: Dāru al-khair, 1994 M/1416 H), h. 367.

${ }^{23}$ Kamal ibn Sayyid al-Sālim, Sohīh Fiqh Sunnah wa Adillatuhu wa Taudih Mazāhib alA'immah, Juz 3 (Cet. 1; Mesir: Al-maktabah al-Tauqifiyyah, 2003 M), h. 160.

${ }^{24}$ Muhammad Jamāluddin al-Bābarti, al-Ināyah Syarhu al-Hidāyāh, Juz 3 (t.t.; Dār al-Fikr, t.th), h. 316

${ }^{25} \mathrm{Abu}$ al-Qōsim al-Zamahsyarī, Al-Kasyāf al-Hakāiq Gawāmīidi al-Tanzīl, Juz 1 (Cet. 3; Beirut: Dār al-Kitāb al-Arabī, 1407 H), h. 470.

${ }^{26}$ Muhammad al-Rādzi, Mafătīhu al-Qoib, Juz 9 (Cet 3; Beirut: Dār Ihya al-Turōsi al-Arabī, 1420 H), h. 491.

${ }^{27}$ Muhammad Sayyid Tontowi, Al-Tafsir al-Wasit Iì al-Qur'ān al-Karìm, Juz 3 (Cet. 1; Mesir: Dār Nahdah, 1997 M), h. 37.

${ }^{28}$ Husain ibn Audah al-Awāyisah, al-Mausuatu al-Fiqhiyyah al-Muyassarah fì Fiqhi al-Kitāb wa al-Sunnah al-Mutahharah, Juz 5 (Cet. 1; Beirut: Al-Maktabah al-Islāmiyyah, 1423 H), h. 55. 
mahar, sebagaimana dalam sabda beliau yang artinya: "Tidak ada nikah syighār dalam Islam." 29

\section{Mahar Dalam Islam}

Islam memerintahkan untuk seorang laki-laki yang menikah untuk menyiapkan mahar nikah. Adapun mahar nikah sebagai bentuk pemuliaan kepada seorang Wanita. Dalam al-Qur'an Q.S. A-Nisa'/4” 4, Allah Subhānahu wa Ta’āla berfirman:

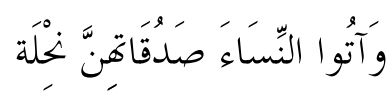

Terjemahnya: "Berikanlah maskwain (mahar) kepada wanita (yang kamu nikahi) sebagai pemberi dengan penuh kerelaan."

Pada ayat tersebut memerintahkan untuk memberi mahar bagi suami kepada istri, sebagaimana yang disebutkan oleh para ulama. Imam Ibnu Katsir dalam tafsirnya mengatakan bahwa: "Adalah seorang laki-laki dahulu ketika menikahkan anak perempuannya maka mahar anaknya diambil, lalu kemudian Allah melarangnya dengan turunnya ayat ini". ${ }^{30}$ Demikian pula apa yang dikatakan oleh Imam Al-Qurtubi dalam tafsirnya, ${ }^{31}$ dan Imam Al-Tobari ${ }^{32}$ bahwa ayat tersebut sebagai perintah kepada laki-laki yang akan menikah untuk memberi mahar sebagai pemberian yang wajib dan kewajiban yang harus ditunaikan. Hal ini juga dikuatkan lagi oleh perkataan para ulama tafsir sebagaimana disebutkan dalam buku tafsir al-Maisir yang berbunyi: "Wahai para suami-suami, berikanlah mahar istri-istri kalian sebagai pemberian wajib, dan kewajiban yang harus dengan penuh kerelaan hati yang tulus, dan apabila hati mereka (para istri) memberikan kembali mahar tersebut kepada kalian dengan kerelaan hati juga maka ambillah dan gunakan semaumu karena harta itu sudah menjadi halal." 33

Dalam buku al-Mar'atu baina al-Fiqhu wa al-Qonūn yang ditulis oleh Mustafa

\footnotetext{
${ }^{29}$ Muslim ibn al-Hajjaj al-Naisābūri, Sahih Muslim, Juz 2 (Beirut: Dār Ihya' al-Turōs alArabi, t.th), h. 1035.

${ }^{30}$ Abu al-Fida' ibn katsir, Tafsir al-Qur'ān al-Adzìm, Juz 2 (Cet. 2; Riyad: Dārun Toyyibah Ii al-Nasyri wa al-Tauzi', 1999 M/1420 H), h. 213.

${ }^{31}$ Abu Muhammad Makki al-Qurtubi, Al-Hidāyah Ilā Bulūgi al-Nihāyah, Juz 2 (Cet. 1; Emirat Arab: Jāmiah Syāriqoh, 2008 M/1429 H), h. 1222.

${ }^{32}$ Muhammad ibn Jarir al-Tobari, Jāmi' al-Bayān fì Ta'wīl al--Qur'ān, Juz 7 (Cet. 1; Beirut: Muassasatu al-Risālah, 2000 M/1420 H), h. 552.

${ }^{33}$ Kumpulan Ulama Tafsir, Al-Tafsir al-Maisir (Cet. 2; Saudi Arabia: Mujamma' Malik Fahad, $2009 \mathrm{M} / 1430 \mathrm{H})$, h. 77.
} 
al-Subā'i beliau mengatakan bahwa: "Mahar dalam Islam adalah bentuk pemuliaan kepada wanita dan sebagai bentuk keinginan yang kuat untuk hidup bersama, dan menghilangkan mahar adalah satu bentuk gambaran masyarakat jahiliah dan lalainya akan pengetahuan tentang hikmah dari mahar dan perkawinan." ${ }^{34}$ Demikian pula apa yang dikatakan oleh Wahbah al-Zuhaili dalam bukunya al-Fiqhu al-Islämi wa Adillatuhu, beliau mengatakan: “...Mahar sebagai bukti akan pentingnya akad nikah dan kedudukannya, dan sebagai bentuk pemuliaann wanita dan ketinggian kehormatannya..." ${ }^{35}$ Muhammad Ya'kub alDahlawi dalam bukunya mengatakan tentang mahar kawin: "Diantara landasan yang sangat ditekankan dalam perkara hak-hak dalam berumah tangga, bahwa ada hak yang mencakup hak Allah dan hak hamba sebagaimana hak mahar bagi wanita..." 36

Idah

\section{Pengertian Idah}

Al-Iddah secara bahasa berasal dari kata "al-addu" dan "al-hisāb" yang memiliki arti menghitung sesuatu, dan sebab penamaan tersebut karena cakupan yang dihitung adalah bilangan jumlah haid dan bilangan bulan. ${ }^{37}$ Menurut ulama Hanāfiyyah, al-Iddah secara terminologi memiliki 2 (dua) pengertian yaitu; Pertama, waktu menunggu untuk hilangnya apa yang tersisa dari pengaruh pernikahan atau hubungan tidur. Kedua, masa menunggu yang diketahui setelah terjadinya cerai apakah dari pernikahan yang sahih (benar) atau dari pernikahan yang syubhat. ${ }^{38}$ Menurut ulama Malikiyyah, al-Iddah adalah masa yang terlarang bagi seorang wanita setelah perceraian, atau karena meninggalnya suami atau karena pembatalan nikah oleh pengadilan. ${ }^{39}$ Menurut ulama Syafi'iyyah, AlIddah adalah waktu menunggu bagi seorang perempuan (istri) untuk mengetahui bersihnya rahim dari suami yang telah mentalaknya. ${ }^{40}$ Menurut ulama Hanabilah, Al-Iddah adalah masa menunggu yang dibatasi oleh syariat bagi seorang wanita

\footnotetext{
${ }^{34}$ Mustafa al-Subā'i, Al-Mar'atu Baina al-Fiqh wa al-Qonūn (Cet. 7; Beirut: Dār al-Warrāq 「i al-Nasyri wa al-Tauzi', $1999 \mathrm{M} / 1420$ H), h. 56.

${ }^{35}$ Wahbah al-Zuhaili, Al-Fiqhu al-Islāmi wa Adillatuhu, Juz 9 (Cet. 4; Damaskus: Dār al-Fikr, $2011 \mathrm{M})$, h. 6668.

${ }^{36}$ Muhammad Ya'kūb al-dahlāwi, Domānāt Huqūq al-Mar'ah al-Zaujiyah (Cet. 1; Riyad: AlJāmiah al-Islāmiyah bì al-Madinah, 1424 H), h. 37.

${ }^{37}$ Kamal ibn Sayyid al-Sālim, Sahih Fiqh Sunnah wa Adillatuhu wa Taudihu Mazāhib alA'immah, Juz 3 (Cet. 1; Mesir: Almaktabah al-Tauqifiyyah, 2003 M), h. 317.

${ }^{38}$ Abdurrahman Iwad al-jaziri, Al-Fiqhu Alā' al-Mazāhib al-Arba'ah, Juz 4 (Cet. 2; Beirut: Dār al-Kutub al-Ilmiyyah, 2003 M/1424 H), h. 451.

${ }^{39}$ Abdurrahman Iwad al-Jazīi, Al-Fiqhu Alā' al-Mazāhib al-Arba'ah, Juz 4, h. 454.

${ }^{40}$ Abdurrahman Iwad al-Jazīiri, Al-Fiqhu Alā' al-Mazāhib al-Arba'ah, Juz 4, 455.
} 
yang telah menikah, maka tidak boleh menikah selama masa idah apakah karena meninggal suami atau karena cerai. ${ }^{41}$

\section{Idah Di Masa Jahiliah}

Masa idah bagi seorang wanita di masa jahiliah adalah sebuah keburukan yang sangat tidak manusiawi. Hal tersebut bisa dilihat dari berita langsung yang disampaikan oleh Rasulullah șallallāhu 'alayhi wa sallam dalam sabda-sabda beliau. Diantara apa yang diriwayatkan oleh al-Imam al-Bukhari dalam kitab sahihnya, bahwasanya Nabi șallallāhu 'alayhi wa sallam memberikan gambaran bagaimana wanita yang sedang berada dalam masa idah, bahwa ia masuk ke dalam gubuk dan memakai pakain yang paling lusuh miliknya. Ia tidak boleh menyentuh wewangian hingga berlalu 1 (satu) tahun. Kemudian keledai, kambing atau sebangsa burung didatangkan kepada wanita itu agar ia mengusap kulitnya. Dan sangat jarang ia mengusap sesuatu pun kecuali sesuatu itu akan mati. Setelah itu ia keluar lalu diberi kotoran hewan dan ia lemparkan. Setelah itu ia bebas menyentuh kembali sekehendaknya berupa wewangian ataupun yang lainnya. ${ }^{42}$ Demikian pula apa yang disebutkan dalam kitab Fathul Bāri tentang masa idah wanita di masa jahiliah, bahwa mereka tidak boleh menyentuh air, tidak boleh memotong kuku, tidak boleh memotong rambut, kemudian seteleh genap setahun barulah wanita itu keluar dengan kondisi yang sangat buruk. ${ }^{43}$

\section{Idah Di Masa Islam}

Idah bagi wanita sebagaimana yang telah dijelaskan dalam pengertian Idah, bahwa dia adalah masa menunggu seorang wanita setelah terjadi cerai atau karena meninggalnya suami. Masa Idah telah dijelaskan pensyariatannya dalam al-Qur'an sebagaimana dalam Firman Allah Subhānahu wa Ta'āla :

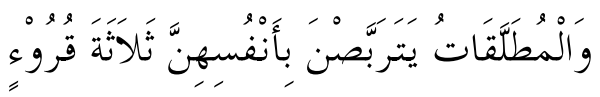

Terjemahnya: "Wanita-wanita yang ditalak hendaknya menahan diri (menunggu)

${ }^{41}$ Abdurrahman Iwad al-Jazīiri, Al-Fiqhu Alā' al-Mazāhib al-Arba'ah, Juz 4 (Cet. 2; Beirut: Dār al-Kutub al-Ilmiyyah, 2003 M/1424 H), h. 451.

${ }^{42}$ Muhammad ibn Ismaìl al-Bukhāri, Sahih al-Bukhāri, Juz 7 (Cet. 1; Damaskus: Dār Touku al-Najāh, 1442 H), h. 59.

${ }^{43}$ Ibnu Hajar al-Asqalāni, Fathul Bāri Syarah Sahih al-Bukhāri, Juz 9 (Cet. 1; Riyad: Dār alMar'rifah, 1421 H), h. 470. 
tiga kali quru'(Q.S. Al-Baqarah/2: 228)"

Sedangkan dalil dari sunah diantaranya adalah hadis dari Ummu Salamah istri Nabi șallallāhu 'alayhi wa sallam yang terjemahannya: "Dari Ummu Salamah istri Nabi șallallāhu 'alayhi wa sallam bahwa seorang wanita dari Aslam bernama Subai'ah ditinggal mati oleh suaminya dalam keadaan dia hamil. Lalu Abi Sanābil ibn Ba'kāk melamarnya, namun ia menolak menikah dengannya. Ada yang berkata, 'demi Allah, dia tidak boleh menikah dengannya hingga menjalani masa idah'. Setelah 10 (sepuluh) malam berlalu, ia mendatangi Nabi șallallāhu 'alayhi wa sallam dan Nabi șallallāhu 'alayhi wa sallam bersabda menikahlah." ${ }^{4}$ Bila di masa jahiliah wanita yang berada di masa idah tidak dibolehkan sama sekali keluar dari gubuk tempat mereka dengan keadaan yang sangat buruk, maka dalam Islam dibolehkan dengan tentunya melalui persyaratan yang telah ditetapkan oleh syariat.

Dalam sebuah hadis Nabi sallallāhu 'alayhi wa sallam, ada kebolehan wanita yang telah ditalak 3 (tiga) (talak bain) untuk keluar rumah dalam rangka mencari nafkah. Nabi șallallāhu 'alayhi wa sallam bersabda yang artinya: "Dari Jabir bin Abdullah radhiallahu 'anhu., dia berkata, 'Bibiku ditalak yang ketiga oleh suaminya, namun beliau tetap keluar rumah untuk mendapatkan kurma (sebagai nafkah), hingga beliau bertemu dengan seseorang yang kemudian melarangnya. Maka bibiku mendatangi Rasulullah șallallāhu 'alayhi wa sallam sambil bertanya tentang hal itu. Dan Rasulullah șallallāhu 'alayhi wa sallam berkata; silakan keluar rumah dan dapatkan nafkahmu, barangkali saja kamu bisa bersedekah dan mengerjakan kebaikan. ${ }^{45}$

Ada juga hadis yang membolehkan bagi wanita di masa idah untuk keluar rumah mengunjungi tetangga, dan hal itu atas pengetahuan Rasulullah șallallāhu 'alayhi wa sallam. "Beberapa laki-laki telah gugur dalam perang Uhud, maka para istri mereka yang saling bertetangga berkumpul di rumah salah seorang dari mereka. Mereka pun mendatangi Rasulullah șallallāhu 'alayhi wa sallam dan bertanya, 'Ya Rasulullah șallallāhu 'alayhi wa sallam, kami merasa khawatir di malam hari dan kami tidur bersama di rumah salah seorang dari kami. Bila hari telah pagi, maka kami kembali ke rumah masing-masing'. Nabi șallallāhu 'alayhi wa sallam bersabda, 'kalian saling menghibur di rumah salah seorang dari kalian. Bila kalian akan tidur, maka kembali masing-masing ke

\footnotetext{
${ }^{44}$ Muhammad ibn Ismail al-Bukhāri, Sahih al-Bukhāri, Juz 7 (Cet. 1; Damaskus: Dār Touku al-Najāh, 1442 H), h.56.

${ }^{45}$ Muslim ibn Hajjāj al-Naisābūrì, Sahih Muslim, Juz 2 (Cet. T.d.; Beirut: Dār Ihya' alTurōts al-Arabi, t.th.), h. 1121.
} 
rumahnya", ${ }^{46}$

Dalam kitab al-Muhalla oleh Ibnu Hazm disebutkan bahwa: "Dari jalur Ismail bin Ishaq telah mengabarkan kepadaku Abu Bakar bin Abi Syaibah telah mengabarkan kepadaku Abdul al-Wahhab Ats-Tsaqafi dari Habib al-Mu'allim, saya pernah bertanya kepada Atha' tentang perempuan yang ditalak 3 (tiga) kali (talak bain) atau perempuan yang ditinggal mati suaminya, apakah keduanya boleh menunaikan ibadah haji ketika masih dalam masa idahnya? Atha' pun menjawab, ya boleh. Dan Al-Hasan (Hasan Al-Basri) juga berpendapat demikian. ${ }^{47}$

\section{KESIMPULAN}

Tujuan yang ingin dicapai dari penelitian adalah untuk mengetahui koreksi hukum Islam terhadap hukum jahiliah. Berdasarkan hasil penelitian ditemukan bahwa poligami yang berlaku di masa jahiliah yaitu dengan tidak membatasi jumlah istri sehingga memberikan dampak sosial buruk dan ketidakadilan Adapun Islam datang membatasi jumlah dengan 4 (empat) istri saja. Demikian pula mahar, dimana di masa jahiliah wanita mendapatkan ketidakadilan dengan tidk memiliki hak mendapatkan mahar, maka Islam mengoreksi dan memberikan hak mahar kepada wanita calon istri. Demikian pula halnya dengan idah yang dimasa jahiliah wanita memiliki idah yang cukup lama, maka Islam dating dengan memberi batasan yang adil terhadap kemaslahatan wanita.

\section{DAFTAR PUSTAKA}

Abdurrahman Iwad al-Jazīi, Al-Fiqhu Alā' al-Mazāhib al-Arba'ah, Juz 4 (Cet. 2; Beirut: Dār al-Kutub al-Ilmiyyah, 2003 M/1424 H).

Abd Moqsith Ghazāli, idah dan ihdad dalam islam: pertimbangan legal formal dan etik moral (Jakarta: LkiS Rahima, 2002 M).

Abu Daud al-Sajastāni, Sunan Abi Daud, Juz 1 (Beirut: al-Maktabah al-Asriyyah, t.th).

Abu Daud Sulaiman al-Sajastāni, Sunan Abu Daud Li al-Arnōt, Juz 3(Cet. I; Beirut: Dār al-Risālah al-Ālamiyyah, 2009 M/1430 H).

Abu al-Fidā' ibn katsīr, Tafsir al-Qur'an al-Adzīm, Juz 2 (Cet. 2; Riyad: Dārun Toyyibah li al-Nasyri wa al-Tauzi', 1999 M/1420 H).

${ }^{46}$ Ahmad ibn Husain al-Baihaqì, Sunan al-Kubro Ii al-Baihaqī, Juz 7 (Cet. 3; Beirut: Dār alKutub al-Ilmiyyah, $2003 \mathrm{M} / 1424 \mathrm{H})$, h.717.

${ }^{47}$ Ibnu Hazam al-Andalūsī, Al-Muhalla bì al-Atsār, Juz 10 (Cet. t.d.; Beirut: Dār-al-Fikr, t.th. ), h. 79 . 
Ahmad ibn Husain al-Baihaqi, Sunan al-Kubro Ii al-Baihaqi, Juz 7 (Cet. 3; Beirut: Dār al-Kutub al-Ilmiyyah, 2003 M/1424 H).

Abu al-Hasan al-Nadawi, Mădza Khasira al-Alam bï Inhitöti al-Muslimīn (Cet. 1; Mesir: Maktabatu al-Imān Mansūrah, t.th).

Abu Muhammad Makki al-Qurtubi, Al-Hidāyah Ilā Bulūgi al-Nihāyah, Juz 2 (Cet.

1; Emirat Arab: Jāmiah Syāriqoh, 2008 M/1429 H).

Abu al-Qōsim al-Zamahsyāri, Al-Kasyāf al-Hakā'iq Gawāmidi al-Tanzīl, Juz 1 (Cet. 3; Beirut: Dār al-Kitāb al-Arabi, 1407 H).

Agus Hermanto, Islam, Poligami dan perlindungan perempuan, kalam 9, no. 1 (2015). h. 167.

Ali Abdul Wāhid Wāfi, "Hukūk al-Insān fi al-Islām", (1429 H).

Fāyiq Muhammad Ganāyim, al-Qiyam wa al-Ibar, wa al-Amtsāl fì al-Qur'ān alKarīm (Urdun: Dārul Ma'mūn Ti al-Munsyir wa al-Tauzi''), h. 13.

Haris Hidayatullah, “Adil Dalam Poligami Perspektif Ibnu Hazm”, Studi Islam 6, no 2 (2015): h. 207-236.

Husain ibn Audah al-Awāyisah, al-Mausūatu al-Fiqhiyyah al-Muyassarah fí Fiqhi al-Kitāb wa al-Sunnah al-Mutahharah, Juz 5 (Cet. 1; Beirut: Al-Maktabah al-Islamiyyah, $1423 \mathrm{H}$ ).

Kamal ibn Sayyid al-Sālim, Sahīh Fiqh Sunnah wa Adillatuhu wa Taudihu Mazāhib al-A'immah, Juz 3 (Cet. 1; Mesir: Almaktabah al-Tauqifiyyah, $2003 \mathrm{M})$.

Kumpulan Ulama Tafsir, Al-Tafsir al-Maisir (Cet. 2; Saudi Arabia: Mujamma' Malik Fahad, $2009 \mathrm{M} / 1430 \mathrm{H}$ ).

Ibnu Abi Hatim, Tafsir al-Qur'an al-Azim Li ibn Abi Hātim, Juz 3 (Cet. 3; Saudi Arabia: Maktabah Naz̄ar Mustafa al-Baz̄, 1995 M/1419 H).

Ibnu Hajar al-asqalāni, Fathul Bāri Syarah Sahīh al-Bukhāri, Juz 9 (Cet. 1; Riyad: Dār al-Mar'rifah, $1421 \mathrm{H})$.

Ibnu Hazam al-Andalūsi, Al-Muhalla bỉ al-Atsār, Juz 10 (Cet. t.d.; Beirut: Dāral-Fikr, t.th. ).

Ibnu Katsir, Tafsìr al-Qur'ān al-Adzìm, Juz 2 (Cet. 2; Riyad: Dārun Thoyyibah Ii al-Nasyrì' wa al-

Jamaluddin ibn Mandzūr, Lisānul Arab Juz 5 (Cet. 3; Beirut: Dārun Shōdirūn, $1414 \mathrm{H})$.

Kamal ibn Sayyid al-Sālim, Sohīh Fiqh Sunnah wa Adillatuhu wa Taudih Mazāhib al-A'immah, Juz 3 (Cet. 1; Mesir: Al-maktabah al-Tauqifiyyah, $2003 \mathrm{M})$.

Muhammad Arif Mustofa, "Poligami Dalam Hukum Agama Dan Negara", alImarah 2, no. 1 (2018): h. 48.

Muhammad ibn Idris al-Syafi'ī, Tafsīr al-Imām al-Syafi'í, Juz 2 (Cet. I; Saudi Arabia: Dār al-Tadmūriyyah, 2006 M/1427 H), h. 515. 
- al-Bayān, Juz 7 (Cet. 1; Beirut: Muassatu al-Risālah, 2000 M/1420 H).

Muhammad ibn Ismail al-Bukhāri, Sahīh al-Bukhāri, Juz 7 (Cet. 1; Damaskus: Dār Touku al-Najāh, 1442 H).

Muhammad Jamaluddin al-Bābarti, al-Inayāh Syarhu al-Hidāyah, Juz 3 (t.t.; Dār al-Fikr, t.th).

Muhammad al-Rādzi, Mafătīhu al-Qoib, Juz 9 (Cet 3; Beirut: Dār Ihya al-Turōsi al-Arabi, $1420 \mathrm{H}$ ).

Muhammad Sayyid Tontōwi, Al-Tafsìr al-Wasit Ii al-Qur'ān al-Karīm, Juz 3 (Cet. 1; Mesir: Dār Nahdah, 1997 M).

Muhammad Ya'kūb al-dahlāwi, Domānāt Huqūq al-Mar'ah al-Zaujiyyah (Cet. 1; Riyad: Al-Jā'miah al-Islāmiyyah bī al-Madinah, $1424 \mathrm{H}$ ).

Mujiddin al-Jazāri ibn al-Asīr, Al-Syāfí 'i fì Syarhi Musnadi al-Syāfíí, Juz 4 (Cet. 1; Riyad: Maktabah al-Rusydi, 2005 M/1426 H).

Muslim ibn al-Hajjaj al-Naisāburi, Sahih Muslim, Juz 2 (Beirut: Dār Ihya' alTurōs al-Arabi, t.th).

Mustafa al-Subā'i, Al-Mar'atu Baina al-Fiqh wa al-Qonūn (Cet. 7; Beirut: Dār alWarraq Ti al-Nasyri' wa al-Tauzi', 1999 M/1420 H).

Rahman, R. A. (2016). Konsep Keadilan dalam al-Quran. NUKHBATUL'ULUM: Jurnal Bidang Kajian Islam, 2(1), 167-175.

Riadhiyati Khafidhoh, "tinjauan fiqih tentang mahar sebagai pemberian atau pembelian”, Skripsi (Jepara: Fak. Syariah dan Hukum UNISNU Jepara, 2015), h. 1-4.

Saguni, M. K. (2018). Meluruskan Beberapa Persepsi tentang Poligami (Tafsir Surat al-Nisa'Ayat 3 dan 129). NUKHBATUL'ULUM: Jurnal Bidang Kajian Islam, 4(2), 161-172.

Sayyid Qutub, Ma'ālim fī al-Torìq (Cet. 6; Beirut: Dār al-Syurūq, 1399 H/1979 $\mathrm{M})$.

Taqiyuddin al-Syafi'‘’, Kifāyatu al-Akhyār fì Halli Göyatu al-Ikhtisōr (Cet. 1; Damaskus: Dār al-Khair, 1994 M/1416 H).

Wahbah al-Zuhaili, Al-Fiqhu al-Islämi wa Adillatuhu, Juz 9 (Cet. 4; Damaskus: Dār al-Fikr, $2011 \mathrm{M})$. 